\title{
Selective Hydrophilization of the Permeate Surface to Enhance Flux in Membrane Distillation
}

\author{
Smruti Ragunath, Sagar Roy, Somenath Mitra* \\ Department of Chemistry and Environmental Science, New Jersey Institute of Technology \\ Newark, NJ, 07102 USA \\ * Corresponding Author \\ Somenath Mitra, 973-596-5611(t), 973-596-3586(F), mitra@njit.edu
}




\begin{abstract}
This paper reports the development of novel hydrophilized membrane for water desalination using direct contact membrane distillation (DCMD). The permeate side of a porous polytetrafluoroethylene (PTFE) membrane on polypropylene (PP) support was hydrophilized by chemical treatment with oxidizing agents to enhance the rapid condensation and removal of permeated vapors. Depending upon the process conditions, permeate flux was as high as 61 $\mathrm{L} / \mathrm{m}^{2} . \mathrm{hr}$, and as much $73 \%$ higher than an unmodified membrane. $58 \%$ increase in overall mass transfer coefficient was also observed with the hydrophilized membrane. In short, hydrophilization of membrane surface showed enhanced flux at lower temperature, making this a more energy efficient process.
\end{abstract}

Keywords: Direct contact membrane distillation, Surface hydrophilization, Desalination, Mass transfer coefficient. 


\section{Introduction:}

Desalination of sea and brackish water is commercially carried out by methods such as multi stage flash distillation (MSF), multiple effect desalination (MED), and reverse osmosis (RO). These techniques have their limitations such as high energy consumption and equipment cost [1, 2]. At this point there is a need to develop cost effective low temperature processes that can utilize industrial waste heat and solar energy to desalinate water.

Recent studies [3] show that membrane distillation (MD) as a promising alternative that involves the transport of vapors through a micro porous, hydrophobic membranes $[4,5]$. The driving force is provided by the vapor pressure gradient across the membrane [6, 7]. The advantages of $\mathrm{MD}$ is that it can be operated at lower temperatures $\left(60\right.$ to $\left.90^{\circ} \mathrm{C}\right)$, does not require large vapor space as in MSF, is less prone to fouling than RO, can generate high purity water and can handle water with high salt concentrations. All of these advantages make it attractive for the production of high purity water where low quality industrial heat is available in the form of boiler blow downs, flue gasses, or low pressure steam [8-10]. MD has also been used with thermally sensitive food and pharmaceutical products [11]. Various modes of MD have been developed where the condensing medium varies from cold distillate to a sweep gas or vacuum [6].

MD is carried out using hydrophobic micro porous membranes to facilitate selective water vapor transport. Different membranes in flat-sheet or hollow fiber forms, made of polytetrafluoroethylene (PTFE), polypropylene (PP), and polyvinylidene-di-fluoride (PVDF) have been used in MD $[12,13]$. Several techniques such as phase inversion and stretching of dense films have been used to make MD membranes, and hydrophilic membranes have been 
surface treated to enhance hydrophobicity [14]. Composite membranes consisting sandwiched hydrophobic/hydrophilic layers has also been reported [15-21].

Despite various advantages, the potential of MD is yet to be fully realized. MD processes often show poor permeate flux due to increased heat loss, mass transfer resistance, trapped air within membrane pores, pore wetting and temperature polarization $[22,23]$. Much effort has gone into developing methods for enhancing the performance of the membranes by modifying membrane surface including immobilization of nanoparticles and nano carbons [24, 25]. An important consideration is the fast removal of water vapors in the permeate side of the membrane to increase the concentration gradient for mass transfer. This is applicable for all types of MD [6]. As the water vapor comes through, it needs to be rapidly condensed and removed. While the feed side of the membrane needs to be highly hydrophobic to prevent pore wetting, it is feasible to have a more hydrophilic permeate surface so that it would have higher affinity to the water vapor, and consequently facilitate its rapid removal. The objective of this research is to enhance MD flux by selective hydrophilization of the permeate side of the membrane. A more specific objective is to study this phenomenon in direct contact membrane distillation (DCMD) where pure water is used to collect the permeated water vapors.

\section{Experimental}

\subsection{Materials and methods}

MD experiments were carried out in the DCMD mode [26]. The schematic diagram of the experimental setup is shown in Fig.1. Typical setup consists of a PTFE membrane cell having an effective membrane area of $14.5 \mathrm{~cm}^{2}$. The membrane holder had Viton O-rings, PTFE tubing, 
PFA and PTFE connectors, as well as pumps for feed and permeate flow. The system has been described before [26-28]. Constant temperature water bath (Neslab Waterbath Model GP 200, NESLAB Instruments, Inc, Newington, NH, USA) was used to maintain steady feed temperature and a bench top chiller (Polyscience LS5, Cole-Parmer, USA) was used to maintain the permeate temperature around $15-20^{\circ} \mathrm{C}$. Feed and permeate solutions were contacted in the membrane module in a counter current flow. Both the feed and permeate were recycled from their respective reservoirs using Master Flex Easy Load peristaltic pumps (Cole-Parmer, USA). The inlet and outlet membrane temperatures were monitored using temperature sensors (Four-channel Data logging Thermometer, RS-232, Cole-Parmer, USA). Hydrophobic Teflon membrane of 0.2 $\mu \mathrm{m}$ pore size with polypropylene support was obtained from Advantec (Toyo Roshi Kaish,Ltd, Japan).

2.2 Membrane hydrophilization

The membrane under study was a highly hydrophobic Teflon membrane with polypropylene support. Surface modification via chemical treatment of the polypropylene backing was carried out to enhance the hydrophilicity of the permeate side. The process was initiated with treatment with chromic acid solution which was prepared by mixing potassium dichromate $\left(\mathrm{K}_{2} \mathrm{Cr}_{2} \mathrm{O}_{7}\right)$, sulfuric acid and water in a ratio of 1:20:30 [29]. After preliminary wetting in acetone, the membrane was treated with the chromic acid solution for $1 \mathrm{~min}$ in an oven maintained at $60^{\circ} \mathrm{C}$. The membrane was then washed with distilled water.

The hydrophilization was characterized by measuring the contact angle of water droplet on membrane surface, Fourier transform infrared (FTIR) spectroscopy (Magna IR System 560, 
Nicolet Instrument Corporation, Wisconsin, USA) and Scanning Electron Microscope with Energy Dispersive X-ray (SEM-EDX) Spectroscopy (Leo 1530 VP, Carl Zeiss SMT AG Company, Oberkochen, Germany). All characterization was performed three times and average was reported. Performance of the hydrophilized membrane was compared with that of the unmodified membrane by determining the flux at different flow rates, temperature and salt concentration. All experiments were repeated three times and the relative standard deviation for the experiments was estimated to be within $1 \%$.

\section{Result and discussion}

\subsection{Membrane characterization}

The membrane was characterized using Scanning Electron Microscopy (SEM) along with Energy Dispersive X-ray (EDX) Spectroscopy [30-32]. Fig. 2 (a) shows the SEM image of the membrane permeate side while figures 2 (b) and (c) show EDX images of the permeate side before and after hydrophilization. The EDX analysis of permeate side of the membrane showed an increase in oxygen content from 1.5 to $7 \%$ after hydrophilization.

The hydrophilicity of the modified membrane was also studied by contact angle measurements. A low contact angle on the permeate side can lead to the pore wetting of the membrane by increased surface energy [33]. After hydrophilization, the contact angle was found to decrease from $94^{\circ} \pm 2$ to $73^{\circ} \pm 2$. Lowering contact angle via partial hydrophilization in the permeate side of the membrane was expected to have positive effect on the membrane performance. The photographs of the contact angle measurements performed at the permeate side of both the hydrophilized and unmodified membrane are shown in Fig. 3 (a) and (b). 
Chemical hydrophilization on the permeate side introduced polar functionalities such as carbonyl and hydroxyl groups on the surface, which were confirmed using FTIR analysis. Fig. 3 (c) shows the presence of strong C-H stretch at $2800-3000 \mathrm{~cm}^{-1}$ and $\mathrm{C}-\mathrm{H}$ bending around $1350-$ $1480 \mathrm{~cm}^{-1}$ which were attributed to polypropylene backbone. The presence hydroxyl stretch between $3200-3600 \mathrm{~cm}^{-1}$ and at $3500-3700 \mathrm{~cm}^{-1}$ were observed after hydrophilization along with the carbonyl stretch between $1670-1820 \mathrm{~cm}^{-1}$. There was also slight shift in the $\mathrm{C}-\mathrm{H}$ to $2820-$ $2850 \mathrm{~cm}^{-1}$.

\subsection{Effect of hydrophilization on membrane performance}

The overall permeate flux was calculated as follows:

$$
J=\frac{w_{p}}{t . A}
$$

where $w_{p}$ is the total mass of the permeate, $\mathrm{t}$ is the permeate collection time and $\mathrm{A}$ is the membrane surface area. The performance of the membranes was studied as a function temperature, flow rate and salt concentration.

As seen in Fig. 4a, the water vapor flux increased with temperature in both of the membranes. This was attributed to the exponential increase in vapor pressure with temperature $[34,35]$. It was seen that the hydrophilized membranes exhibited higher water vapor flux compared to the unmodified membrane. Maximum water vapor flux of $61.4 \mathrm{~L} / \mathrm{m}^{2} . h r$ was attained at $80^{\circ} \mathrm{C}$ feed temperature at a permeate flow of $200 \mathrm{~mL} / \mathrm{min}$ for the hydrophilized membrane. The effect of hydrophilization of the permeate side was quite dramatic with an enhancement as high as $52 \%$ at $60^{\circ}$ C. Fig. 4 (b) presents a plot of vapor pressure difference on permeate flux. As 
expected similar trend was obtained with increasing vapor pressure difference on permeate flux for both membranes.

Fig. 4 (c) shows the effect of varying feed flow rate at $60^{\circ} \mathrm{C}$ at a constant permeate flow rate of $200 \mathrm{~mL} / \mathrm{min}$, while Fig. 4 (d) shows the effect of varying permeate flow rate at the same temperature but at constant feed flow rate of $200 \mathrm{~mL} / \mathrm{min}$. Higher flux were observed in both cases. Nearly $73 \%$ enhancement was attained at $100 \mathrm{~mL} / \mathrm{min}$ and $60^{\circ} \mathrm{C}$ for hydrophilized membrane at constant feed flow rates. The increase in water vapor flux for increasing flow rate was attributed to the increased turbulence and reduced boundary layer effect at elevated flow rates which helped in lowering the temperature polarization and increased the driving force for MD.

Fig. 4 (e) shows the effect of varying feed concentration on permeate flux. The high salt concentration decreased the water activity at the membrane interface. A significant boundary layer developed along the membrane interface at high feed concentrations which reduced the driving force across the membrane. This led to a decrease in permeate flux. As expected, overall water vapor flux decreased with increase in salt concentration ranging from $61.4 \mathrm{~L} / \mathrm{m}^{2} . \mathrm{hr}$ and 45 $\mathrm{L} / \mathrm{m}^{2} . \mathrm{hr}$ for pure water to $42.9 \mathrm{~L} / \mathrm{m}^{2} . \mathrm{hr}$ and $35.7 \mathrm{~L} / \mathrm{m}^{2} . \mathrm{hr}$ at $10000 \mathrm{ppm}$ concentration for hydrophilized and unmodified membrane, respectively.

The rate of mass transfer across the membrane is given as:

$$
\begin{gathered}
J w=k\left(P_{f}-P_{p}\right) \\
k=J_{w} /\left(P_{f}-P_{p}\right)
\end{gathered}
$$


where $J$ is the water vapor flux of the system, $k$ mass transfer coefficient, $P_{f}$ and $P_{p}$ are partial vapor pressure of average feed and permeate temperatures. The mass transfer coefficients were found to be significantly higher for hydrophilized membrane as compared to unmodified membrane.

Table.1 summarizes the effect of varying flow rate and permeate flow rate on mass transfer coefficient respectively. At lower flow rates, overall mass transfer was controlled by diffusion through the boundary layers. However, with increase in flow rates, turbulence increased, thereby reducing the boundary layer resistance and significantly increasing the mass transfer coefficients. Both membranes exhibited similar phenomena with increase in flow rate. Overall mass transfer coefficients in the hydrophilized membrane increased from $4.1 \times 10^{-07}$ to $6.1 \times 10^{-07}$ with increase in feed flow rate, and $5.5 \times 10^{-07}$ to $6.1 \times 10^{-07}$ with increase in permeate flow rate. The enhancements attained were as high as $58 \%$ over the unmodified membrane.

\subsection{Proposed Mechanism}

Permeation in DCMD depends upon temperature difference across the membrane surface. The vapor-liquid separation at the membrane interface on the feed side typically generates an air gap, which reduces pore wetting but increases temperature polarization (shown in Fig.6(a)) [33, 36]. On the other hand, the air gap on the permeate side reduces mass transfer coefficient, and prevents rapid water vapor condensation. As shown in the Fig. 6 (b), the partial hydrophilization on permeate side of the membrane allowed rapid condensation, destabilized the air-gap on the permeate side and reduced the mass transfer barrier between the membrane surface and bulk 
permeate $[33,37]$. Together these led to an increased temperature gradient across the membrane thus increasing the overall flux .

\section{Conclusion}

Enhanced flux in DCMD using a hydrophilized membrane is reported. It was evident that hydrophilization was effective in rapid permeate removal thus enhancing mass transfer coefficients. The membrane distillation performance was consistently higher in case of hydrophilized membranes at all flow rates, temperature and salt concentrations. Flux enhancement reached as high as $73 \%$. 


\section{References}

[1] N.M. Wade, Distillation plant development and cost update, Desalination, 136 (2001) 3-12.

[2] F. Banat, R. Jumah, M. Garaibeh, Exploitation of solar energy collected by solar stills for desalination by membrane distillation, Renewable Energy, 25 (2002) 293-305.

[3] P.S. Goh, T. Matsuura, A.F. Ismail, N. Hilal, Recent trends in membranes and membrane processes for desalination, Desalination.

[4] J. Koschikowski, M. Wieghaus, M. Rommel, Solar thermal-driven desalination plants based on membrane distillation, Desalination, 156 (2003) 295-304.

[5] Z. Ding, L. Liu, M.S. El-Bourawi, R. Ma, Analysis of a solar-powered membrane distillation system, Desalination, 172 (2005) 27-40.

[6] K.W. Lawson, D.R. Lloyd, Membrane distillation, Journal of Membrane Science, 124 (1997) $1-25$.

[7] Z. Lei, B. Chen, Z. Ding, Membrane distillation, Special Distillation Processes, Elsevier Science, Amsterdam, (2005) 241-319.

[8] V. Calabrò, E. Drioli, F. Matera, Membrane distillation in the textile wastewater treatment, Desalination, 83 (1991) 209-224.

[9] M. El-Bourawi, Z. Ding, R. Ma, M. Khayet, A framework for better understanding membrane distillation separation process, Journal of Membrane Science, 285 (2006) 4-29. [10] V. Calabro, B.L. Jiao, E. Drioli, Theoretical and experimental study on membrane distillation in the concentration of orange juice, Industrial \& engineering chemistry research, 33 (1994) 1803-1808. 
[11] A. Cassano, C. Conidi, F. Tasselli, Clarification of pomegranate juice (Punica Granatum L.) by hollow fibre membranes: analyses of membrane fouling and performance, Journal of Chemical Technology \& Biotechnology, 90 (2015) 859-866.

[12] Y. Fujii, S. Kigoshi, H. Iwatani, M. Aoyama, Y. Fusaoka, Selectivity and characteristics of direct contact membrane distillation type experiment. II. Membrane treatment and selectivity increase, Journal of Membrane Science, 72 (1992) 73-89.

[13] R.E. Kesting, Synthetic polymeric membranes: a structural perspective, Wiley NY etc., 1985.

[14] J.F. Kim, J.H. Kim, Y.M. Lee, E. Drioli, Thermally induced phase separation and electrospinning methods for emerging membrane applications: A review, AIChE Journal, 62 (2016) 461-490.

[15] D.R. Lloyd, S.S. Kim, K.E. Kinzer, Microporous membrane formation via thermallyinduced phase separation. II. Liquid-liquid phase separation, Journal of Membrane Science, 64 (1991) 1-11.

[16] D.R. Lloyd, K.E. Kinzer, H. Tseng, Microporous membrane formation via thermally induced phase separation. I. Solid-liquid phase separation, Journal of Membrane Science, 52 (1990) 239-261.

[17] S.S. Kim, G.B.A. Lim, A.A. Alwattari, Y.F. Wang, D.R. Lloyd, Microporous membrane formation via thermally-induced phase separation. V. Effect of diluent mobility and crystallization on the structure of isotactic polypropylene membranes, Journal of Membrane Science, 64 (1991) 41-53. 
[18] K.s. McGuire, D.R. Lloyd, G.B.A. Lim, Microporous membrane formation via thermallyinduced phase separation. VII. Effect of dilution, cooling rate, and nucleating agent addition on morphology, Journal of Membrane Science, 79 (1993) 27-34.

[19] Y. Kong, X. Lin, Y. Wu, J. Chen, J. Xu, Plasma polymerization of octafluorocyclobutane and hydrophobic microporous composite membranes for membrane distillation, Journal of Applied Polymer Science, 46 (1992) 191-199.

[20] Y. Wu, Y. Kong, X. Lin, W. Liu, J. Xu, Surface-modified hydrophilic membranes in membrane distillation, Journal of Membrane Science, 72 (1992) 189-196.

[21] G.B.A. Lim, S.S. Kim, Q. Ye, Y.F. Wang, D.R. Lloyd, Microporous membrane formation via thermally-induced phase separation. IV. Effect of isotactic polypropylene crystallization kinetics on membrane structure, Journal of Membrane Science, 64 (1991) 31-40.

[22] L. Martínez, J.M. Rodríguez-Maroto, Effects of membrane and module design improvements on flux in direct contact membrane distillation, Desalination, 205 (2007) 97-103. [23] L. Martínez-Díez, M.I. Vazquez-Gonzalez, Temperature and concentration polarization in membrane distillation of aqueous salt solutions, Journal of Membrane Science, 156 (1999) 265273.

[24] V. Vatanpour, M. Esmaeili, M.H.D.A. Farahani, Fouling reduction and retention increment of polyethersulfone nanofiltration membranes embedded by amine-functionalized multi-walled carbon nanotubes, Journal of Membrane Science, 466 (2014) 70-81.

[25] E. Bet-moushoul, Y. Mansourpanah, K. Farhadi, M. Tabatabaei, TiO2 nanocomposite based polymeric membranes: A review on performance improvement for various applications in chemical engineering processes, Chemical Engineering Journal, 283 (2016) 29-46. 
[26] M. Bhadra, S. Roy, S. Mitra, Flux Enhancement in Direct Contact Membrane Distillation by Implementing Carbon Nanotube Immobilized PTFE Membrane, Separation and Purification Technology.

[27] S. Roy, M. Bhadra, S. Mitra, Enhanced desalination via functionalized carbon nanotube immobilized membrane in direct contact membrane distillation, Separation and Purification Technology, 136 (2014) 58-65.

[28] M. Bhadra, S. Roy, S. Mitra, Enhanced desalination using carboxylated carbon nanotube immobilized membranes, Separation and Purification Technology, 120 (2013) 373-377.

[29] S. Roy, C.M. Hussain, S. Mitra, Poly (acrylamide-co-acrylic acid) hydrophilization of porous polypropylene membrane for dehumidification, Separation and Purification Technology, 107 (2013) 54-60.

[30] Z.-K. Xu, X.-J. Huang, L.-S. Wan, Surface engineering of polymer membranes, Springer Science \& Business Media, 2009.

[31] B. Tylkowski, I. Tsibranska, Overview of main techniques used for membrane characterization, Journal of Chemical Technology and Metallurgy, 50 (2015) 3-12. [32] A. De los Rios, F. Hernández-Fernández, F. Tomás-Alonso, J. Palacios, D. Gómez, M. Rubio, G. Villora, A SEM-EDX study of highly stable supported liquid membranes based on ionic liquids, Journal of Membrane Science, 300 (2007) 88-94.

[33] L.F. Dumée, S. Gray, M. Duke, K. Sears, J. Schütz, N. Finn, The role of membrane surface energy on direct contact membrane distillation performance, Desalination, 323 (2013) 22-30. [34] J.I. Mengual, M. Khayet, M.P. Godino, Heat and mass transfer in vacuum membrane distillation, International Journal of Heat and Mass Transfer, 47 (2004) 865-875. 
[35] A. Criscuoli, M.C. Carnevale, E. Drioli, Modeling the performance of flat and capillary membrane modules in vacuum membrane distillation, Journal of Membrane Science, 447 (2013) 369-375.

[36] S. Nejati, C. Boo, C.O. Osuji, M. Elimelech, Engineering flat sheet microporous PVDF films for membrane distillation, Journal of Membrane Science, 492 (2015) 355-363.

[37] M. Khayet, J.I. Mengual, T. Matsuura, Porous hydrophobic/hydrophilic composite membranes: Application in desalination using direct contact membrane distillation, Journal of Membrane Science, 252 (2005) 101-113. 


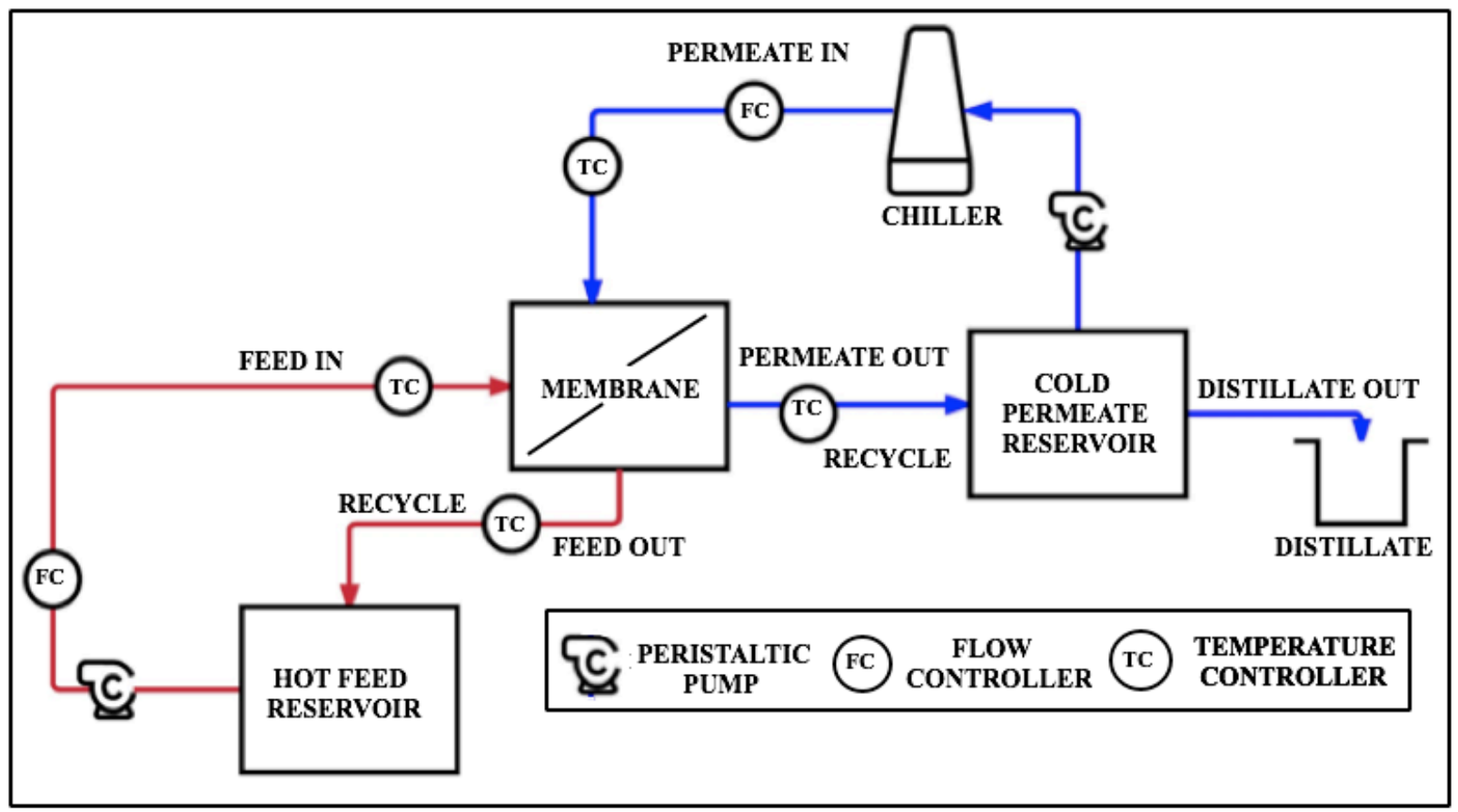

Fig.1 Experimental setup for direct contact membrane distillation using hydrophilized membrane 


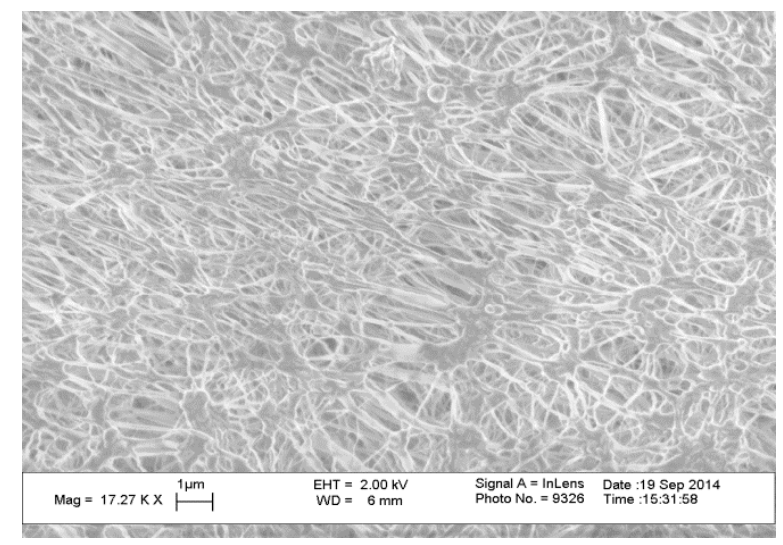

(a)

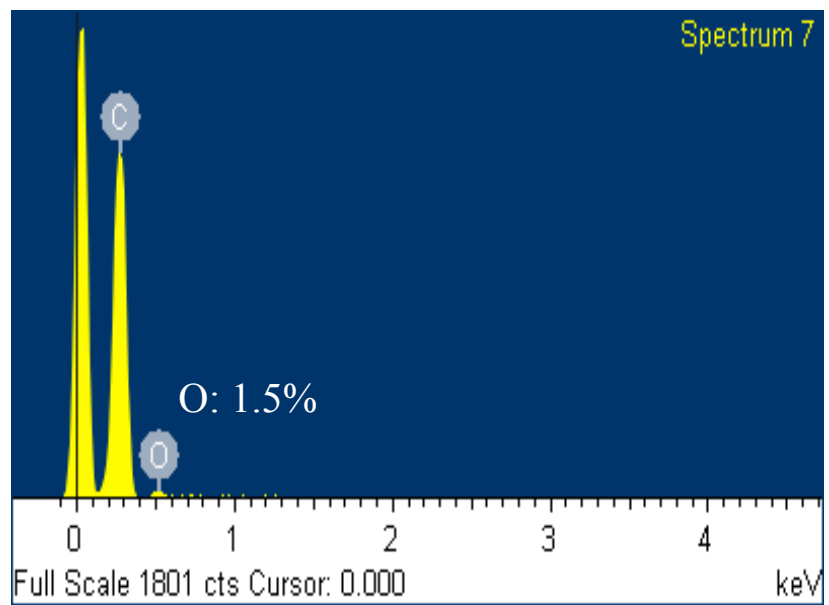

(b)

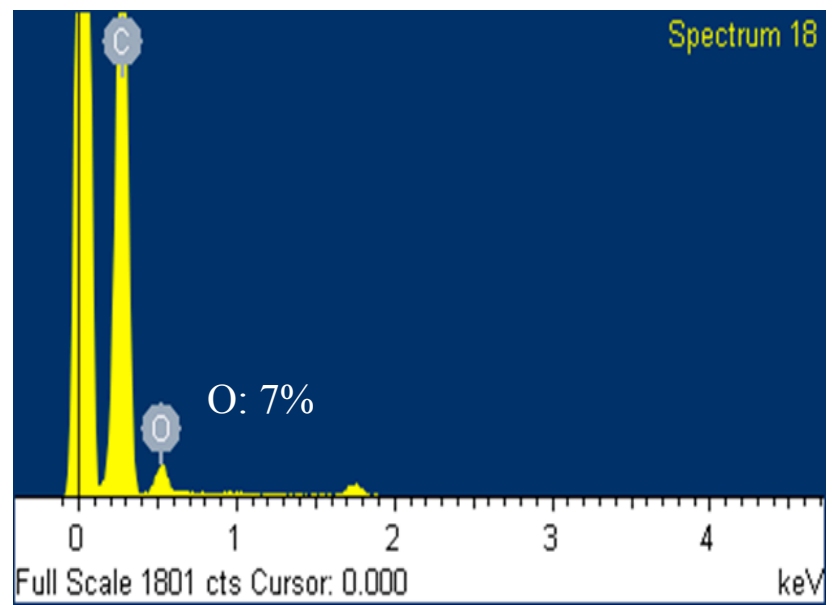

(c)

Fig.2 SEM image and EDX analysis: (a) SEM of the permeate side of membrane, (b) EDX of unmodified permeate side and (c) EDX of hydrophilized membrane. 


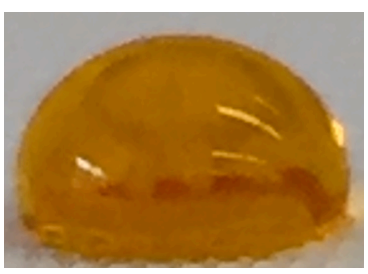

(a)

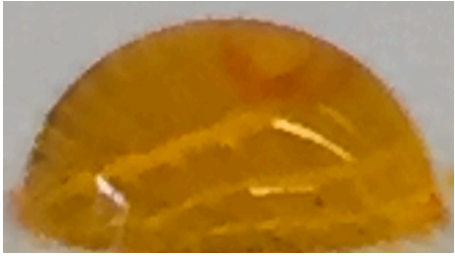

(b)

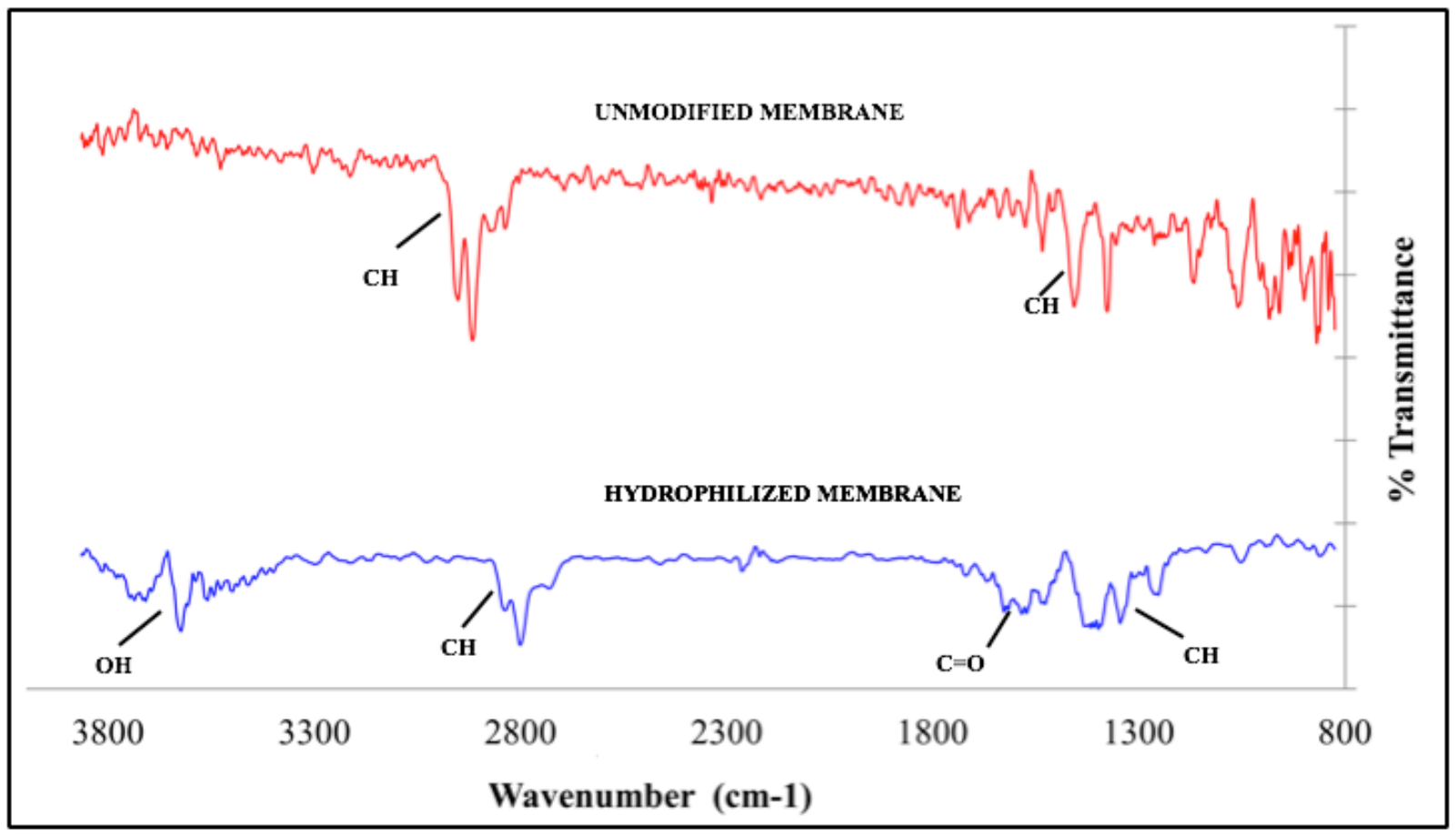

(c)

Fig.3 Water contact angle measurement for (a) Hydrophilized membrane, (b) Unmodified Membrane, (c) FTIR spectra of unmodified and hydrophilized membrane. 


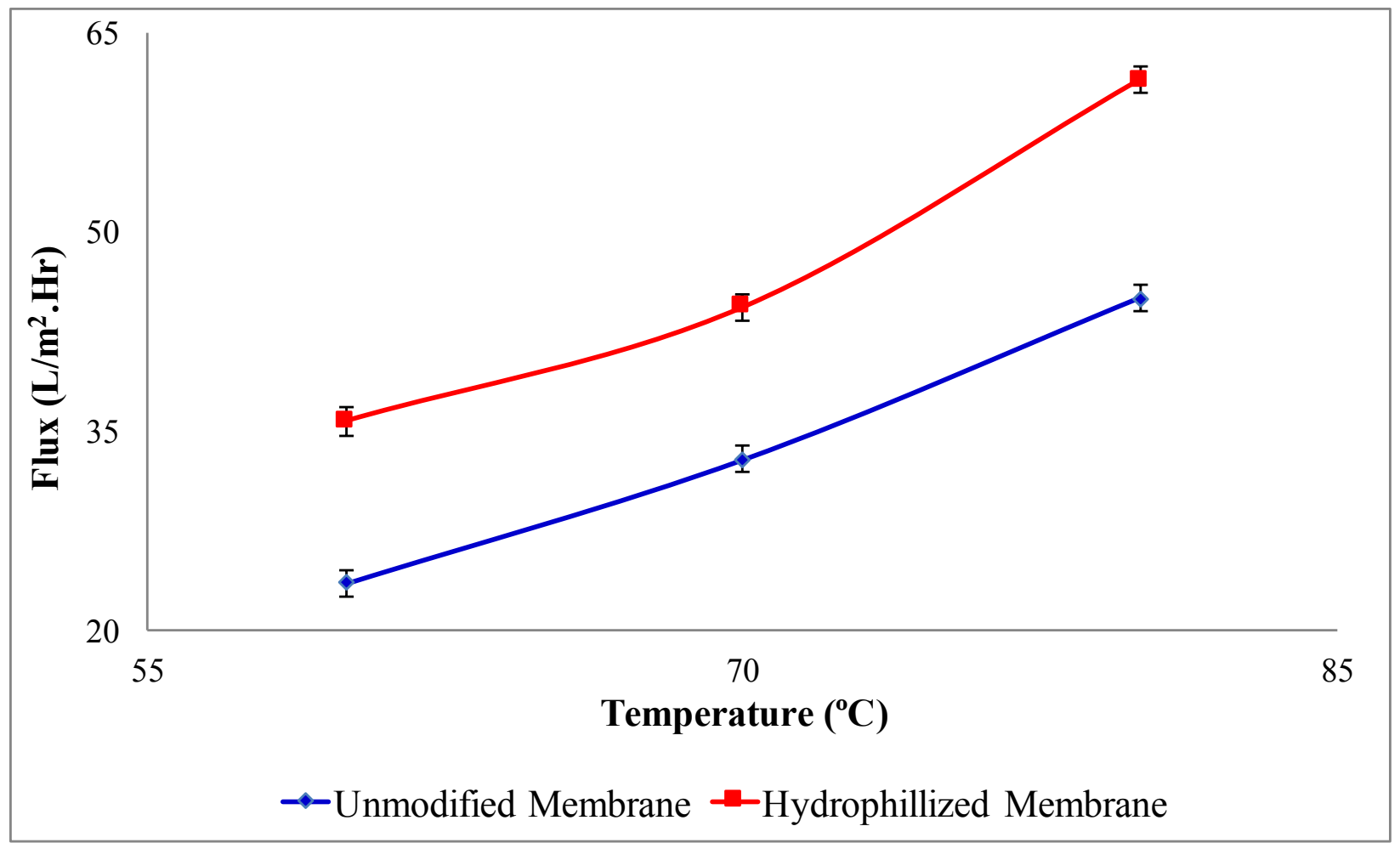

(a)

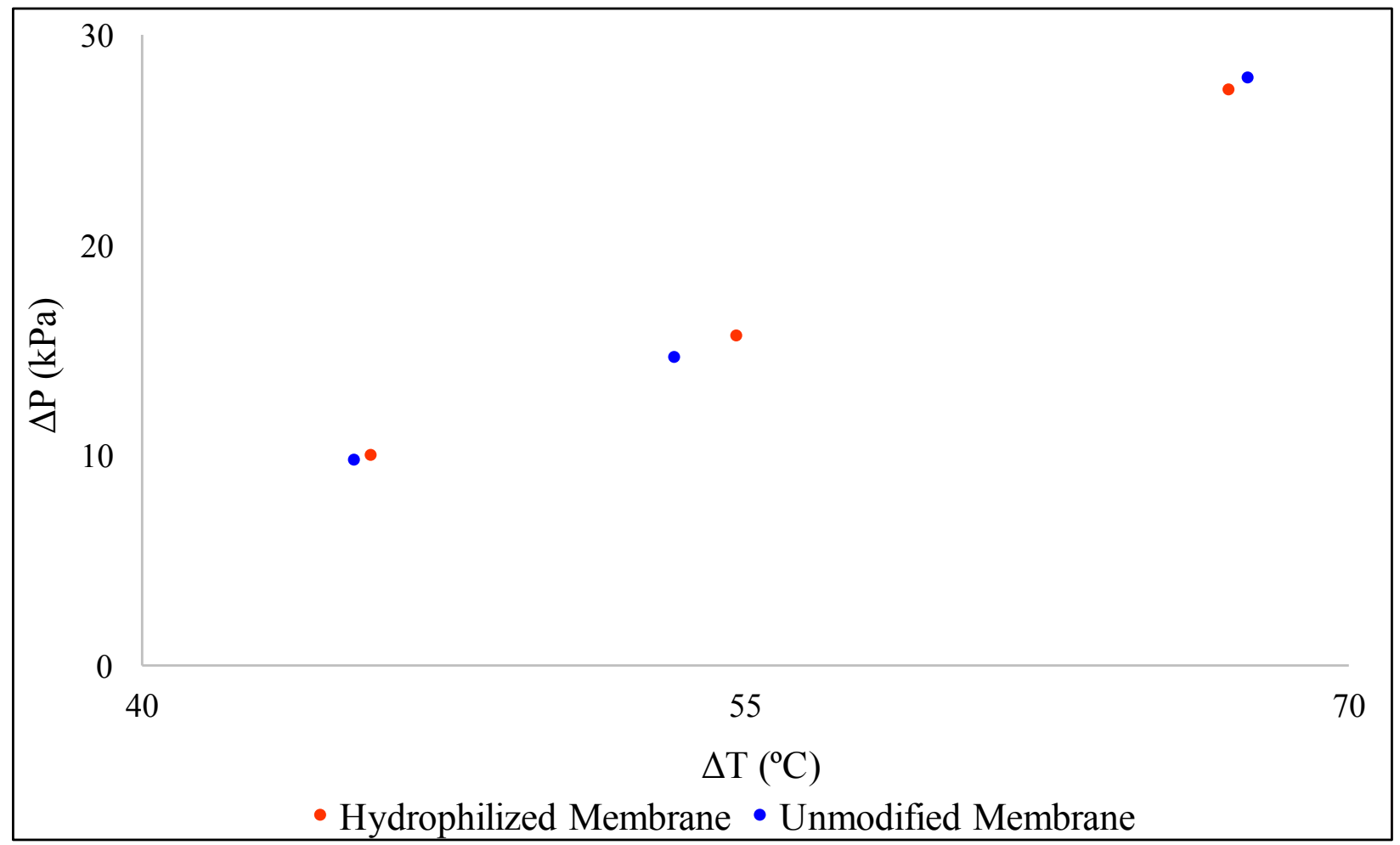

(b) 


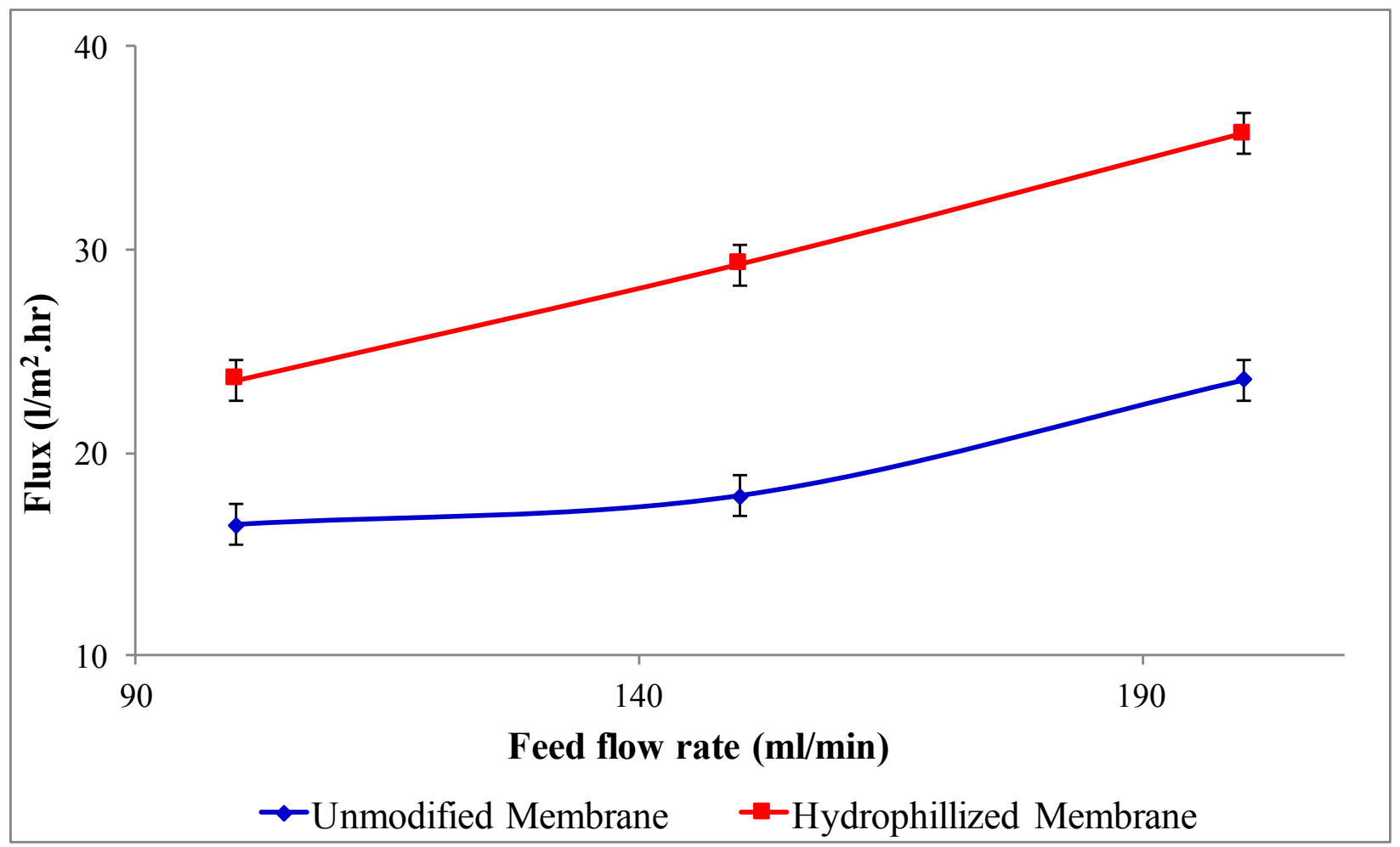

(c)

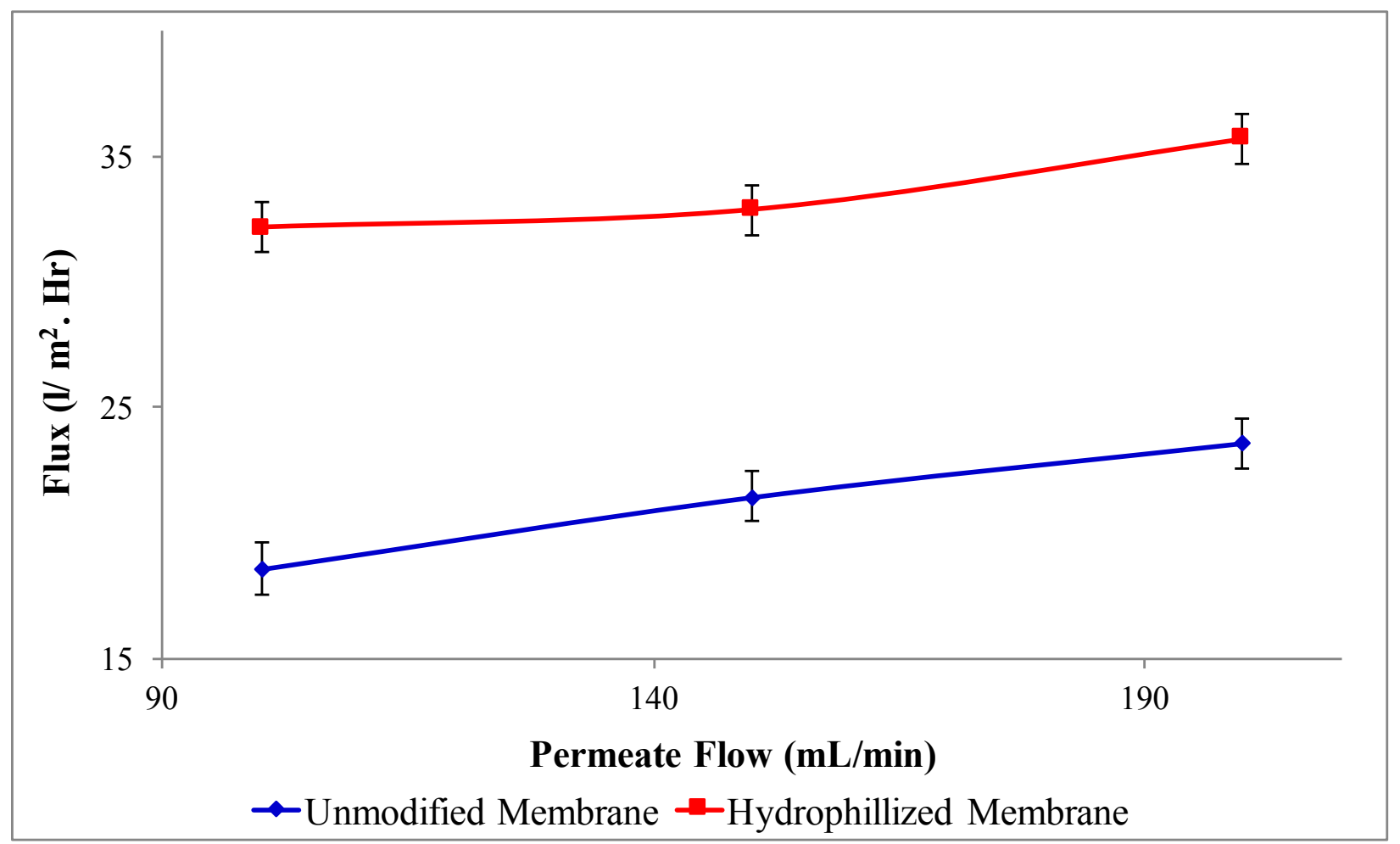

(d) 


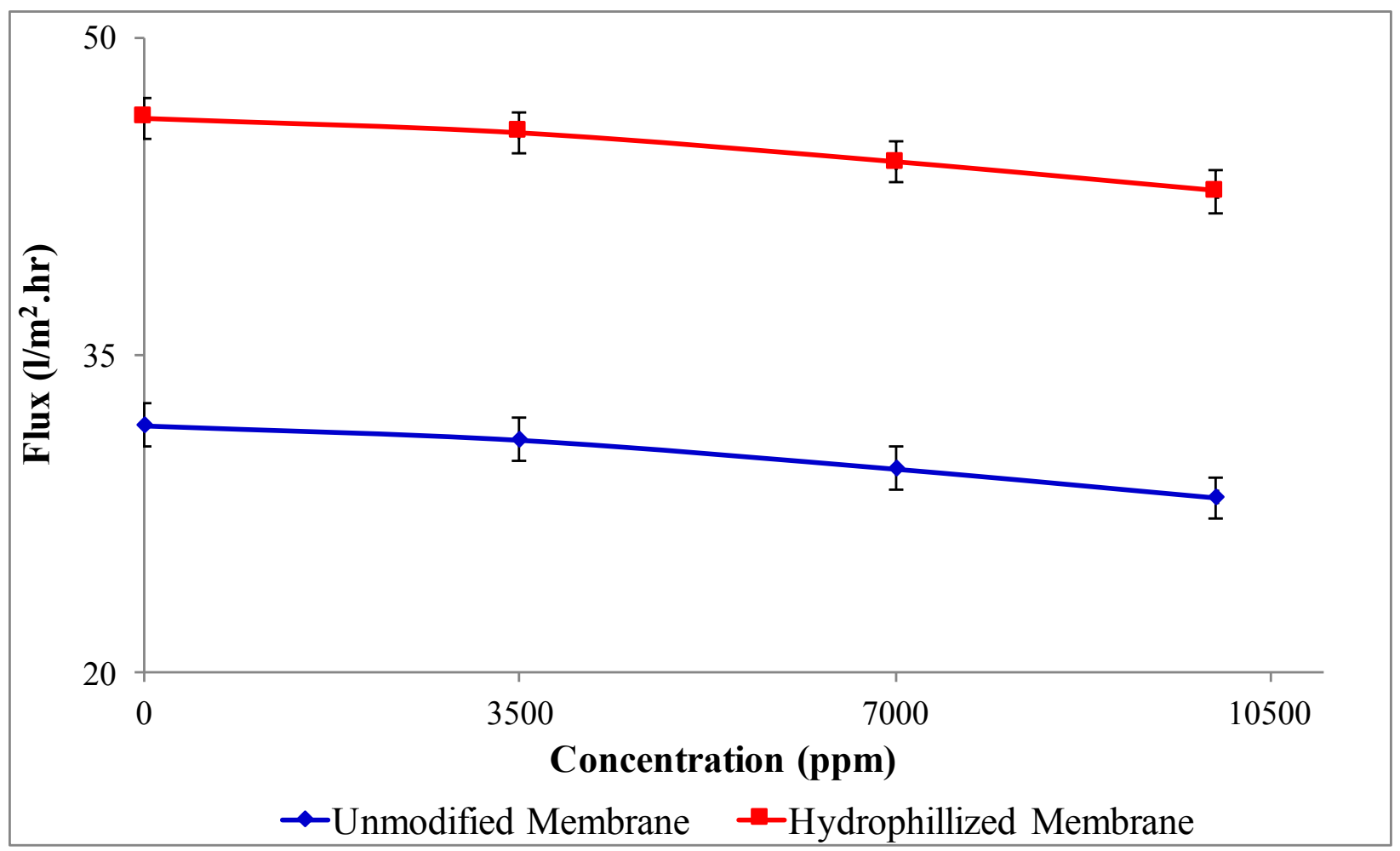

(e)

Fig.4 (a) Effect of temperature on water vapor flux at a feed flow rate of $200 \mathrm{~mL} / \mathrm{min}$; (b) Plot of temperature gradient versus vapor pressure gradient; (c) Effect of feed flow rate variation on water vapor flux at feed temperature of $60^{\circ} \mathrm{C}$; (d) Effect of permeate flow rate variation on water vapor flux at operating temperature of $60^{\circ} \mathrm{C}$; (e) Effect of varying feed concentration on water vapor flux at a feed flow rate of $200 \mathrm{~mL} / \mathrm{min}$ and operating temperature of $70^{\circ} \mathrm{C}$. 
Table.1(A) Effect of varying feed flowrate on mass transfer coefficient at constant temperature; (B) Effect of varying permeate flowrate on mass transfer coefficient at constant temperature.

\begin{tabular}{|c|c|c|}
\hline \multirow{2}{*}{ A } & \multicolumn{2}{|c|}{$\mathrm{k}\left(\mathrm{kg} / \mathrm{m}^{2} . \mathrm{s} . P a\right) \times 10^{-07}$} \\
\hline Feed flowrate $(\mathrm{mL} / \mathrm{min})$ & Hydrophilized Membrane & Unmodified Membrane \\
\hline 100 & 4.2 & 2.9 \\
\hline 150 & 5.2 & 3.0 \\
\hline 200 & 6.1 & 3.9 \\
\hline & \multicolumn{2}{|c|}{$\mathrm{k}\left(\mathrm{kg} / \mathrm{m}^{2} . \mathrm{s} . P a\right) \times 10^{-07}$} \\
\hline B & Hydrophilized Membrane & Unmodified Membrane \\
\hline 100 & 5.5 & 3.3 \\
\hline 150 & 5.7 & 3.7 \\
\hline 200 & 6.1 & 3.9 \\
\hline
\end{tabular}




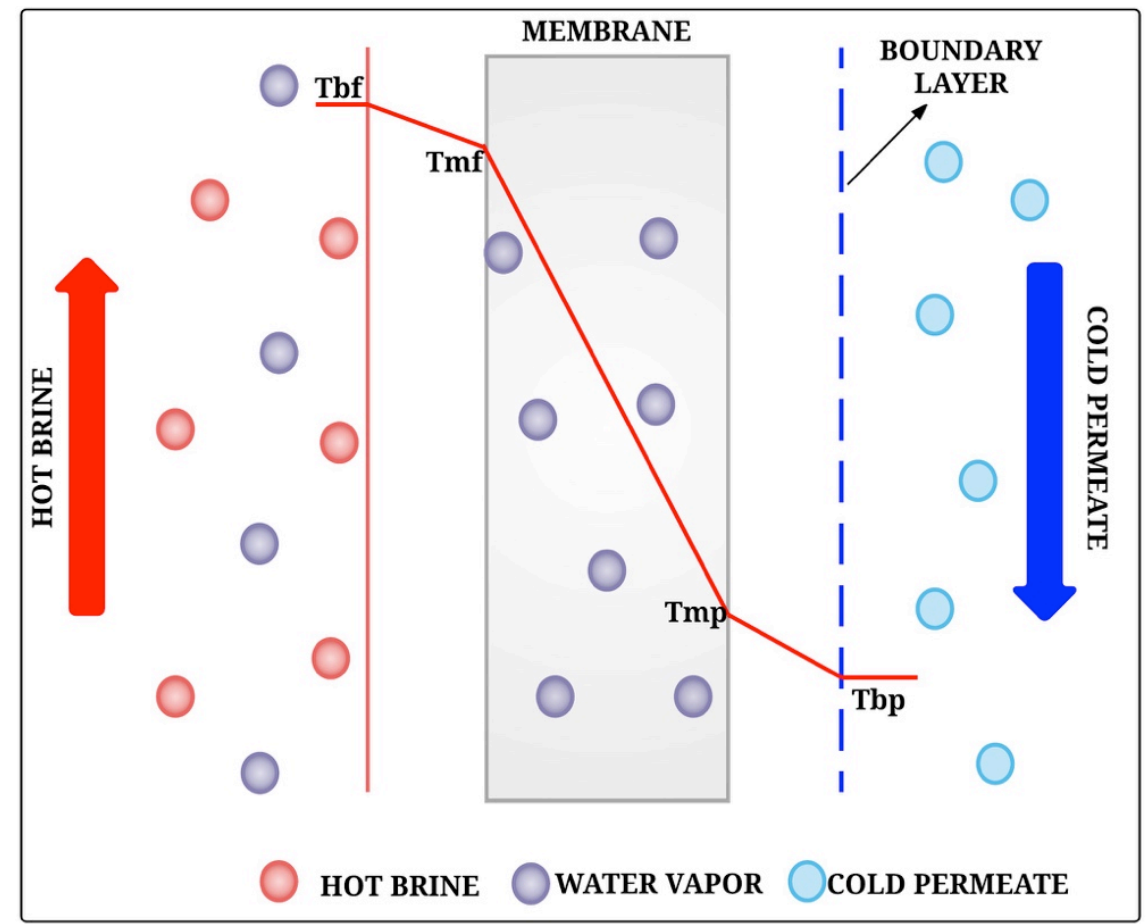

(a)

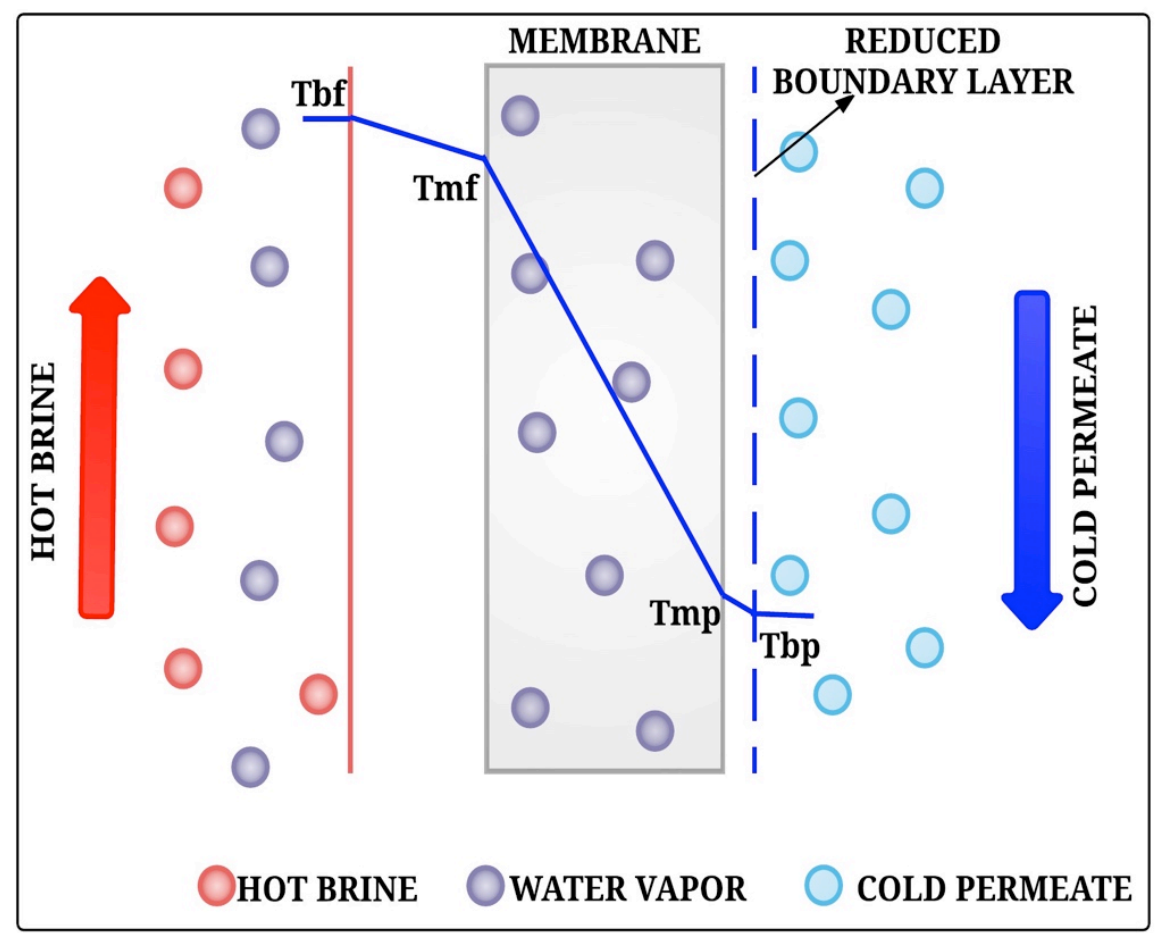

(b)

Fig.6 Proposed mechanism for (a) Unmodified Membrane (b) hydrophilized membrane MD system. 